\title{
A New, Ultra-low-cost Power Quality Measurement Technology
}

\author{
Alex McEachern ${ }^{1}$ and Andreas Eberhard ${ }^{2}$ \\ ${ }^{1}$ President \\ ${ }^{2}$ Vice President of Technical Services \\ Power Standards Lab \\ 1201 Marina Village Parkway \#101, Alameda, California 94501 (United States) \\ Phone:++1-510-522-4400, e-mail: Alex@PowerStandards.com, AEberhard@PowerStandards.com
}

\begin{abstract}
IEC $61000-4-30$ is an excellent standard that ensures that all compliant power quality instruments, regardless of manufacturer, will produce the same results when connected to the same signal. However, instruments that comply with the Class A requirements of this standard have, until now, been too expensive for common use.
\end{abstract}

Now a new set of technologies developed by an American company, in cooperation with a Japanese company, demonstrate that it is possible to manufacture three-phase power quality instruments that are fully compliant with the Class A requirements of IEC 61000-4-30 at ultra-low-cost (selling price less than 500 Euros in quantity).

The development uses technologies from several fields that have not previously been related to power quality, including digital cameras, power-over-ethernet, mobile phones, and submarine sonar systems.

These new technologies have been packaged in a demonstration instrument, and may be licensed to instrument manufacturers as well.

\section{Key words}

Power quality, instrument, meter, low cost

\section{Introduction}

Traditionally, power quality instruments have been complex and expensive - often several thousand Euro.

The cost of power quality instruments is driven by five factors:

1. The cost of developing the instruments

2. The quantity of instruments produced - the more instruments that are produced, the lower the development cost in each instrument

3. The cost of manufacturing the instruments

4. The cost of installation, especially the cost of the communication infrastructure

5. The cost of supporting the instruments, especially the cost of supporting special-purpose software, throughout the life of the instruments.
Remarkably, in the last few years, all of these costs have been driven down simultaneously.

This paper describes the technologies in a new, ultra-lowcost power quality instrument, and explains why the costs are so low.

\section{Reduction in development costs}

Traditional power quality instruments have been developed, from the start, as special purpose instruments. Hardware, firmware, and software have all been developed specifically for that instrument.

However, several developments in other, unrelated industries have made that approach unnecessary.

First, the wide-spread development of digital audio (mobile phones, mobile music players, digital television, etc.) has led to rapid developments in the DSP (digital signal processor) field. New DSP chips are inexpensive, use minimal power, and have built-in analog-to-digital and digital-to-analog conversion. Best of all, they are optimized for processing multiple channels of $20 \mathrm{~Hz}$ to $20 \mathrm{kHz}$ signals. By coincidence, power quality measurements are generally made between $50 \mathrm{~Hz}$ and 3 $\mathrm{kHz}$ - right in the middle of the optimum band. The popularity of the $\operatorname{Ipod} \AA$ means cheaper, better power quality monitors.

Second, the development of relatively complex portable devices (PDA's, mobile phone that also have computer functions, digital cameras, etc.) means that extremely tiny, high-reliability electronic devices are now readily available: connectors with large numbers of pins, tiny op amps, and passive components like resistors and capacitors. Tiny means cheap, in general, if the manufacturing is completely automatic. 


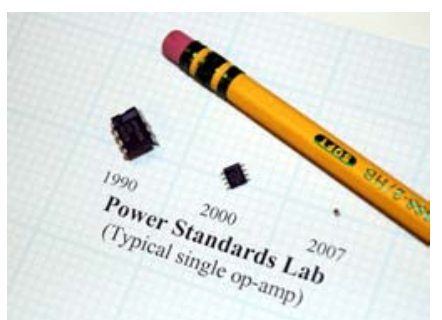

Figure 1: Reduction in component size. Smaller components reduce costs in several ways: smaller printed wiring boards, smaller plastic packages, even smaller power supply requirements. The packages shown are, from left, through-hole DIP, surface mount, and BGA or ball-grid-array.

Third, the availability of high-voltage $(1 \mathrm{kV})$, low current op amps, which are generally used for driving submarine sonar transducers, means that automatic test equipment for power quality instruments can be developed far more cheaply now.

Finally, software standards for file structures mean that just like digital cameras - a power quality instrument developers no longer need to define and support their own file structures. In fact, Windows ${ }^{\circledR}$ text files and web-based graphic file formats have become virtually universal.

Of course, some extraordinarily difficult problems must still be solved by the instrument engineer. How should one deal with a $6 \mathrm{kV}$ lightning impulse in such a tiny package? How can one meet the creepage and clearance requirements in the safety standards? Most important of all, by definition, a power quality instrument must work when the power is bad, and other electronic devices are failing. How can an engineer design an instrument that survives? But all of these difficult challenges can be met.

\section{Increase in the quantity of power quality instruments}

Traditionally, each country defined its own power quality instrument requirements. This meant that an instrument optimized for France, for example, was unlikely to find acceptance in Brazil, for example. Sometimes the situation was even worse: each electric power company would define its own requirements for power quality measurements.

As a result, the quantity for each instrument design was small, and the fraction of the development cost carried in each instrument was large. A rough example: if developing an instrument costs 1.5 million Euros, and the total expected market is 2000 instruments, each instrument must carry 750 Euros of development costs a significant but not uncommon burden.

Recent IEC standards [1][2][3][4] have solved this problem.
IEC 61000-4-30[1][2], in particular, has defined power quality measurement methods. Class $\mathrm{A}$ in this standard ensures that any two instruments, when connected to the same signal, will produce the same result. Figure 2 and Figure 3 give examples.

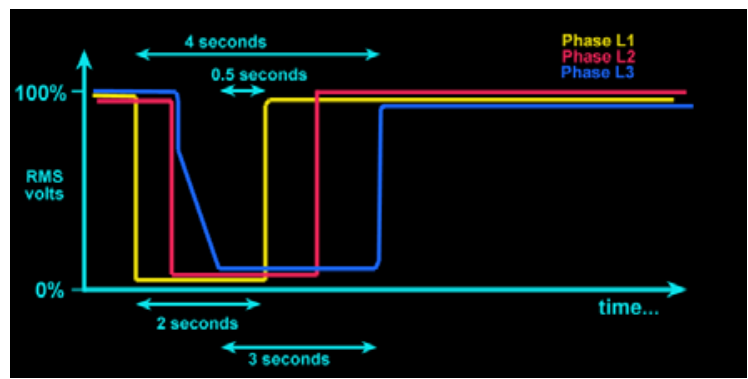

Figure 2. Example of one of the problems solved by IEC 61000-4-30. In the graph of RMS voltages above, what is the duration of the voltage dip? The answers shown range from 0,5 seconds to 4 seconds, and all of them are technically correct. Simply by designating one of these answers as the requirement

( 4 seconds for dip duration measurement, 0.5 seconds for interruption duration measurement), 61000-4-30 reduces cost of instrumentation.

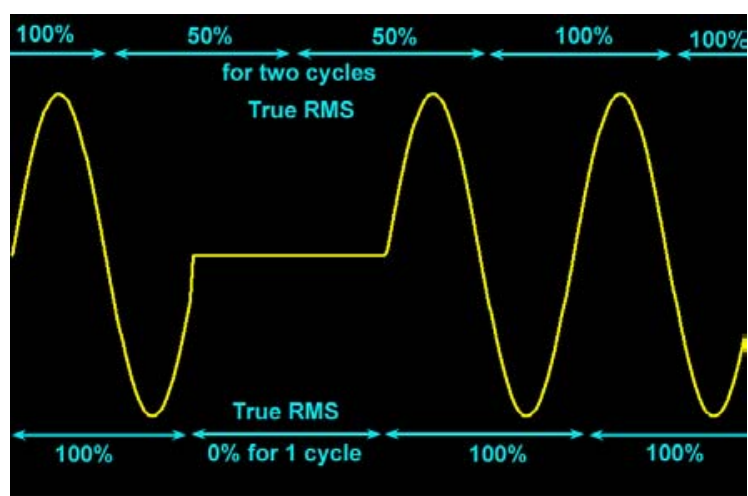

Figure 3. Example of another problem solved by IEC 61000-4 30 . Is this dip $50 \%$ for two cycles, or $0 \%$ for 1 cycle? Again, both answers are technically correct. 61000-4-30 makes it clear that this is a dip to $0 \%$ for 1 cycle - thus reducing cost of instrumentation.

As a result of this IEC standardization, an instrument can be designed for world-wide acceptance, and the total quantity is much higher. This means that the development cost burden is much smaller.

\section{Decrease in manufacturing costs}

Globalization has driven manufacturing costs down.

It is now easy to choose the best sources for parts, worldwide. For example, in the prototype shown in Figure 4, the lower case comes from Germany, the upper case comes from the United States, the display and the memory come from Japan, and the internal electronics are automatically assembled in California using parts from the U.S., Ireland, China, Japan, and other countries. 
Fully-automated manufacturing (robots for placing parts, automatic testing systems for verifying that boards are working properly, automatic calibration systems that adjust internal digital constants, etc.) means that manufacturing costs can be kept very low, even in locations with high labor costs like California, without any sacrifice in quality. Indeed, the quality is generally higher than products that are produced in regions with low labor costs, due to the highly-automated production and test procedures.

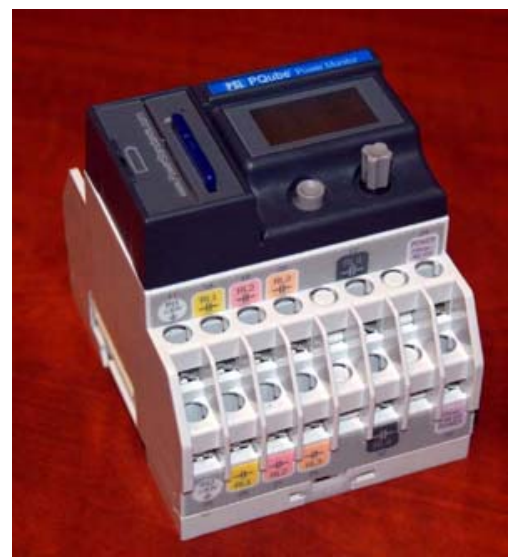

Figure 4. Prototype of the three-phase, voltage-and-current, 61000-4-30 Class A power quality monitor. The digital camera influence can be seen in the SD memory card, which holds up to $2000 \mathrm{MB}$ of data. Standard DIN-rail mounting means installation is cheap and quick.

\section{Decrease in installation and communication costs}

Traditional power quality instruments have been designed with their own unique packaging.

However, they are installed in locations where there are low-voltage circuit breakers. By packaging the power quality instrument in a standard $35 \mathrm{~mm}$ DIN-rail circuit breaker package, installation is greatly simplified.

Perhaps more important, the communication cost of an installed power quality instrument, over the life of the instrument, often exceeds the cost of the instrument itself. Whether the communication is via Ethernet, or telephone modem, or short-distance radio, bringing the communication signal to the monitoring point is a significant cost.

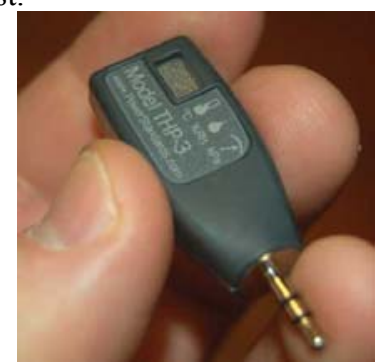

Figure 5. Probes for parameters that may be related to power quality are included: Temperature, Humidity, Barometric Pressure, etc. A GPS satellite receiver can ensure precise timing.
(We should not forget the additional hidden cost of the damage that can be caused to the communication network, during major power disturbances. In regions with strong lightning activity, for example, telephone modems have traditionally been damaged through their connection to power quality monitors.)

Furthermore, in many power quality monitoring applications, immediate communication is not necessary.

The prototype shown in Figure 4 has Ethernet connectivity (and includes a web server, an FTP server, and an e-mail generator), wireless radio connectivity, and a modem connection. However, it is optimized to function without connectivity - it can easily store a year's data on a removable SD memory card.

\section{Decrease in the cost of supporting power quality instruments}

Although it is often hidden from the end user, the lifetime support cost for traditional power quality instruments is significant.

This is especially true for the special-purpose software that was written for each instrument. Often, this software was written for Windows ${ }^{\circledR}$; and the lifetime of a power quality instrument greatly exceeds the lifetime of one release of Windows $\AA$. For example, many power quality instruments are still in use that were originally issued with Windows ${ }^{\circledR} 3.1$ software.

The lifetime costs of upgrading and supporting this software was a major cost.

However, such software is no longer necessary. By following the software model of a digital camera, the prototype power quality instrument of Figure 4 requires absolutely no software. When you connect a digital camera to your computer, you immediately see the pictures in a folder on your disk drive. The same is true for power quality data in the prototype instrument.

By eliminating the need for any software at all, we drive down the costs even further.

Again, this does not eliminate all firmware challenges. The instrument firmware must still support a wide variety of languages and character sets (Japanese, Korean, etc.), and the CSV (comma separated variable) files for spread sheets must work with European systems that use the comma symbol for other purposes. But all of these problems have been previously solved in digital cameras. 


\section{Conclusion}

Recent changes in standards and technology have made it possible to produce a $61000-4-30$ Class A power quality instrument at a very low cost.

A prototype has been constructed, and a fully-automated manufacturing system is being developed.

\section{Acknowledgement}

The first-named author (McEachern) is the Convenor of IEC TC77A Working Group 09, which is responsible for maintaining IEC 61000-4-30 Power Quality Measurement Methods. We gratefully acknowledge the useful and knowledgeable technical contributions of members of this Working Group during discussions and exchanges over the last 10 years. Any errors that remain in this paper, are, of course, entirely the responsibility of the authors.

\section{References}

[1] IEC 61000-4-30, Ed 1, "Testing and measurement techniques - Power Quality Measurement Methods". International Electrotechnical Commission. February 2003.

[2] Corrigendum 1, IEC 61000-4-30, Ed 1. August 2006. [3] IEC 61000-4-15, Ed 1.1, "Flickermeter - Functional and design specifications". International Electrotechnical Commission. 2003.

[4] IEC 61000-4-7 Ed 2, "General guide on harmonics and interharmonics measurements and instrumentation". International Electrotechnical Commission. 2002. 